Note

\title{
Inhibitory Effects of Acidic Xylooligosaccharide on Stress-induced Gastric Inflammation in Mice
}

(Received May 21, 2006)

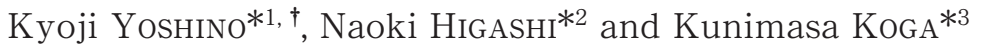 \\ (*1 Department of Chemistry and Biochemistry, Numazu College of Technology: \\ 3600, Ooka, Numazu, Shizuoka 410-8501, Japan; \\ *2Graduate Schools of Human Health Science, Tokyo Metropolitan University: \\ 3-6-33, Azuma-cho, Akishima, Tokyo 196-8540, Japan; \\ ${ }^{*}$ Department of Biological Science and Technology, Tokai University, 317, Nishino, \\ Numazu, Shizuoka 410-0395, Japan; ${ }^{\dagger}$ Corresponding author)
}

\begin{abstract}
The preventive effects of acidic xylooligosaccharide prepared from xylan of corncobs and related sugars on stress-induced gastric inflammation in mice were investigated. Oral administration of acidic xylooligosaccharide and hydrocortisone at doses of 100 and $200 \mathrm{mg} / \mathrm{kg}$ body weight significantly reduced the number of bleeding points in the gastric mucosa of mice loaded with cold-restraint stress. Acidic xylooligosaccharide showed concentration-dependent superoxide anion radical-scavenging activity at concentrations of $3.3-4.3 \mathrm{mg} / \mathrm{mL}$ and its $\mathrm{IC}_{50} \mathrm{was} 3.5 \mathrm{mg} / \mathrm{mL}$, although this value is approximately six times that of quercetin. The antioxidant activity of acidic xylooligosaccharide could contribute, in part, to its suppressive activities on stress-induced mouse gastritis. Xylose, xylobiose, xylan, and glucuronic acid showed no significant suppressive activities on mouse gastric inflammation at a dose of $100 \mathrm{mg} / \mathrm{kg}$ body weight. These results suggest that an appropriate degree of polymerization of xylan (larger than trimer) is necessary for the activities of acidic xylooligosaccharide.
\end{abstract}

Key words: acidic xylooligosaccharide; mouse; stress; gastritis; inflammation; antioxidant activity

\section{Introduction}

Xylan is a major constituent of plant hemicellulose and one of the main components of dietary fiber. Corncobs, bagasse, cereals, bamboo shoots, mushrooms, and cotton hull bran include particularly high levels of xylan. The structure of xylan is variable, ranging from a linear 1,4- $\beta$-linked polyxylose chain to highly branched heteropolysaccharides. The main chain of xylan is composed of D-xylose with 1,3- $\alpha$-linked or 2,1$\alpha$-linked branches consisting of L-arabinofuranose at the $0-3$ positions of $\mathrm{D}$-xylose residues, and of $\mathrm{D}$ glucuronic or $O-2$-methyl-D-glucuronic acid at the $O-2$ positions of $\mathrm{D}$-xylose residues. In some cases, xylan is acetylated at the same positions of D-xylose residues ${ }^{1)}$. Xylan from Hericium erinaceum ${ }^{2)}$ and acidic xylans, including glucuronic acid and 4-O-methylglucuronoxylan, from wood hemicellulose ${ }^{3)}$ show strong suppressive activities against various tumors. Anti-inflammatory activities of 4-O-methylglucuronoxylan from Chamomilla recutita ${ }^{4)}$ and acidic, highly branched heteroxylan from Plantago species ${ }^{5), 6)}$ were also reported. These findings suggest that polysaccharides consisting of xylose and glucuronic acid residues and their degradation products can ameliorate some inflammatory diseases. Xylooligosaccharide, a linear polymer of $1,4-\beta$-linked xylose, is produced industrially by enzymatic degradation of solubilized xylan. It has also been reported that xylooligosaccharide exhibits various beneficial effects, such as improving intestinal condition $^{7}$, decreasing putrefaction products in the intestine ${ }^{8)}$, reducing blood cholesterol level, and suppressing blood glucose level ${ }^{9)}$. An acidic xylooligosaccharide consisting of a linear polymer of $1,4-\beta$-linked xylose bound with glucuronic acid is a byproduct of the production of xylooligosaccharide. However, there have been few reports about its beneficial effects. This oligosaccharide is a water-soluble white powder and has a fresh acidic taste. In view of the recent increase in the incidence of various inflammatory diseases, such as digestive tract ulcers, due to lifestyle-related factors, including dietary habits, we investigated the preventive effects of acidic xylooligosaccharide and related sugars on stress-induced gastric inflammation in mice.

\section{Materials and Methods}

\section{Materials and animals}

$\mathrm{D}(+)$-Xylose (reagent grade quality) and xylobiose (purity $>98 \%$ ) were purchased from Wako Pure Chemical Industries, Ltd. (Osaka, Japan). Xylan (from oats and spelt) was purchased from Tokyo Kasei Kogyo Co., Ltd. (Tokyo, Japan). D-Glucuronic acid (purity 97\%) 
was purchased from Lancaster Synthesis (Morecambe, UK). Acidic xylooligosaccharide from corncobs was supplied by Suntory Ltd. (Osaka, Japan). Acidic xylooligosaccharide consisted of the following components: $4.3 \%$ glucuronoxylose, $17.1 \%$ glucuronoxylobiose, $34.0 \%$ glucuronoxylotriose, $28.8 \%$ glucuronoxylotetraose, $3.8 \%$ glucuronoxylooligomers not less than pentamer, and $12.0 \%$ unknown. The oligomer content was 83.7\%. Quercetin was purchased from SigmaAldrich Co. (St. Louis, MO, USA). Other chemicals used were of reagent grade. Four-week-old male ddY mice were purchased from Japan SLC Inc. (Shizuoka, Japan). Mice were maintained for 3 days in a room at $24 \pm 1^{\circ} \mathrm{C}$ with a $12 \mathrm{hr}$ light-dark cycle and given tap water and commercial laboratory chow (5L37; Japan SLC Inc., Shizuoka, Japan) ad libitum before the experiments. Throughout the experiment, the animals were handled in accordance with "The Guide for the Animal Experiments in Numazu National College of Technology".

\section{Mouse model of stress-induced gastric inflammation}

In this study, cold-restraint stress was used to promote mouse gastritis, because it does not require induction with agents, such as ethanol and hydrochloric acid, thus excluding any direct interaction between the samples and inflammation-inducing agents. The effects of various sugar samples on stress-induced gastric inflammation in mice were examined according to a modification of the method of Chen et al. ${ }^{10)}$ Briefly, 4-weekold male ddY mice were starved for $24 \mathrm{hr}$, but given tap water ad libitum. Samples were dissolved in $0.5 \mathrm{~mL}$ of $0.5 \%(\mathrm{w} / \mathrm{v})$ tragacanth gum solution and administered orally to mice with a gastric sonde at doses of 50,100 , or $200 \mathrm{mg} / \mathrm{kg}$ body weight. Mice were immobilized in stress cages and left at $4^{\circ} \mathrm{C}$ for 90 min under close observation. After stress-loading, the mice were immediately killed under anesthesia with diethyl ether and the stomach was removed. The stomachs were incised in line with the greater curvature and the contents were washed out with chilled saline. The number of bleeding points of $0.5 \mathrm{~mm}$ or more in the inner mucosa of the mouse stomach was counted by visual observation. A control experiment was performed with $0.5 \%(\mathrm{w} / \mathrm{v})$ tragacanth gum solution alone. Hydrocortisone, a wellknown steroid-type anti-inflammatory agent, was administered orally to mice as a positive control at the same doses as the samples. The number of mice in each group was 4 .

\section{Antioxidant activities of acidic xylooligosaccharide}

Antioxidant activities of acidic xylooligosaccharide were evaluated by monitoring superoxide anion radical $\left(\mathrm{O}_{2}{ }^{-\cdot}\right)$-scavenging activity ${ }^{11)}$. Briefly, $0.5 \mathrm{~mL}$ of $15 \mu \mathrm{M}$ phenazine methosulfate, $0.5 \mathrm{~mL}$ of $200 \mu \mathrm{M}$ nitro blue tetrazolium, $0.5 \mathrm{~mL}$ of sample solution, and $0.5 \mathrm{~mL}$ of $750 \mu \mathrm{M}$ nicotinamide adenine dinucleotide, a starter for the production of $\mathrm{O}_{2}{ }^{-} \cdot$, were added to $0.5 \mathrm{~mL}$ of $20 \mathrm{mM}$ phosphate buffer ( $\mathrm{pH}$ 7.4). The mixture was incubated at $25^{\circ} \mathrm{C}$. Formation of nitro blue tetrazolium dif- ormazan was followed spectrophotometrically at 560 $\mathrm{nm}$. The increase in absorption rate of the reaction mixture with samples was compared with that of the mixture without samples, and the inhibition ratio was calculated. The $\mathrm{O}_{2}{ }^{-\cdot}$-scavenging activity of the samples was expressed as the inhibition ratio for the reaction mediated by this radical. The concentrations of the samples used were $3.3-4.3 \mathrm{mg} / \mathrm{mL}$. A natural antioxidant, quercetin, was used at concentrations of $0.78-1.4 \mathrm{mg} / \mathrm{mL}$ as a control.

\section{Statistics}

Statistical analyses were performed with the nonparametric Mann-Whitney $U$-test to determine the significance of differences between groups, and $p<0.05$ was considered statistically significant.

\section{Results and Discussion}

Inhibitory effects of acidic xylooligosaccharide on stressinduced gastric inflammation in mice

The inhibitory effects of acidic xylooligosaccharide on mouse gastric inflammation are shown in Fig. 1. Oral administration of acidic xylooligosaccharide and hydrocortisone at doses of 100 and $200 \mathrm{mg} / \mathrm{kg}$ body weight significantly reduced the number of bleeding points in the gastric mucosa of mice loaded with coldrestraint stress. Hydrocortisone also showed significant suppressive activity on mouse gastric inflammation at a dose of $50 \mathrm{mg} / \mathrm{kg}$ body weight.

As indicated by arrows in Fig. 2, many bleeding points were observed in the gastric mucosa of mice loaded with cold-restraint stress, while no bleeding points were observed in normal healthy mice. Oral administration of acidic xylooligosaccharide at a dose of $100 \mathrm{mg} / \mathrm{kg}$ body weight reduced the number of bleeding points in the gastric mucosa.

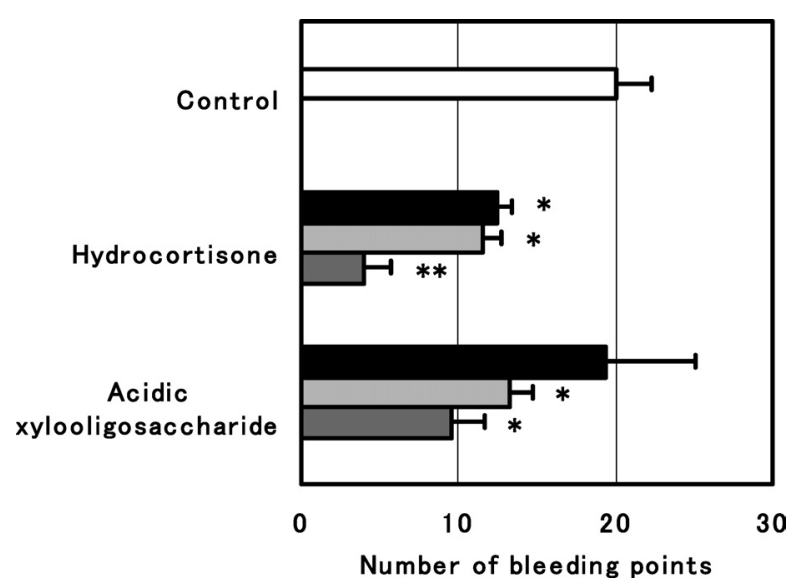

Fig. 1. Inhibitory effects of oral administration of acidic xylooligosaccharide on mouse gastritis induced by cold-restraint stress

Values are means \pm SEM $(n=4)$. Significantly different from the control: $*_{p}<0.05, * *_{p}<0.01$. Dose, $\square$; $50 \mathrm{mg} / \mathrm{kg}$ body weight, _ ; $100 \mathrm{mg} / \mathrm{kg}$ body weight, _ ; $200 \mathrm{mg} / \mathrm{kg}$ body weight. 

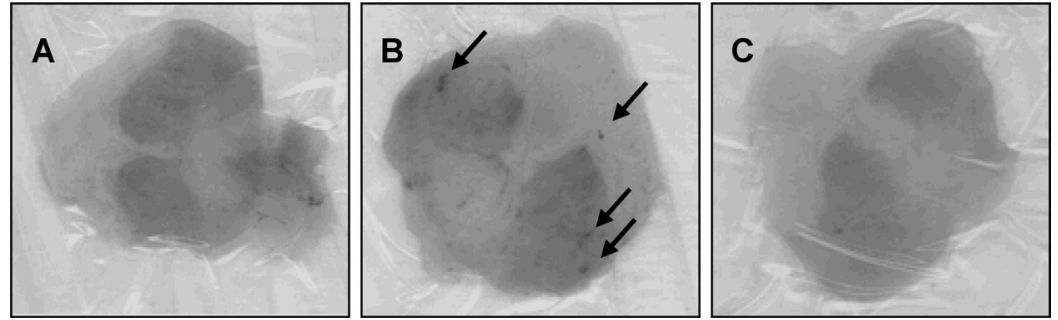

Fig. 2. Inhibitory effects of oral administration of acidic xylooligosaccharide on mouse gastritis induced by cold-restraint stress

A, Normal; B, Control; C, Acidic xylooligosaccharide-supplemented mouse stomach. Dose, $100 \mathrm{mg} / \mathrm{kg}$ body weight. Arrows show the bleeding points.

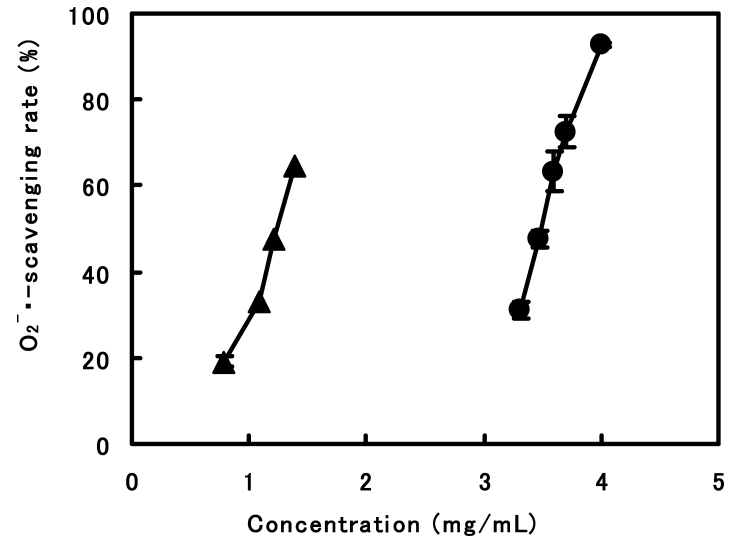

Fig. 3. Superoxide anion radical-scavenging activities of acidic xylooligosaccharide

, acidic xylooligosaccharide; $\boldsymbol{\Lambda}$, quercetin. Values are means $\pm \operatorname{SEM}(n=3)$.

\section{Antioxidant activities of acidic xylooligosaccharide}

Hydrochloric acid and digestive enzymes, such as pepsin, in gastric juice are thought to be direct causative factors of gastritis. Injury to the cells of the inner mucosa in the stomach may stimulate the production of active oxygen species, such as nitrogen monoxide and superoxide anion radicals, by macrophages and neutrophils permeating into them. Active oxygen species could injure the surrounding cells and extracellular matrix, and produce lipid peroxides and metabolites of arachidonic acid. The inflammation would be promoted through these processes ${ }^{12), 13)}$. It was reported that the levels of lipid peroxides were elevated in rats exposed to water-immersion restraint stress ${ }^{14)}$. Chitooligosaccharide and agarooligosaccharide are known to exhibit antioxidant activities ${ }^{15), 16)}$. The $\mathrm{O}_{2}{ }^{-} \cdot$-scavenging activities of acidic xylooligosaccharide are shown in Fig. 3 (values are means of three independent experiments). Acidic xylooligosaccharide showed concentrationdependent $\mathrm{O}_{2}{ }^{-} \cdot$-scavenging activity at concentrations of $3.3-4.3 \mathrm{mg} / \mathrm{mL}$ and its $\mathrm{IC}_{50}$ was $3.5 \mathrm{mg} / \mathrm{mL}$, although the $\mathrm{IC}_{50}$ of quercetin, a common flavonoid in constituents of ordinary meals, was $0.61 \mathrm{mg} / \mathrm{mL}$. The concentrations of the solutions of acidic xylooligosaccharide administered to mice at doses of 50, 100, and $200 \mathrm{mg} /$ $\mathrm{kg}$ body weight were approximately 2,4 , and $8 \mathrm{mg} / \mathrm{mL}$, respectively. Therefore, the $\mathrm{O}_{2}{ }^{-\cdot}$-scavenging activity of acidic xylooligosaccharide could contribute, in part,

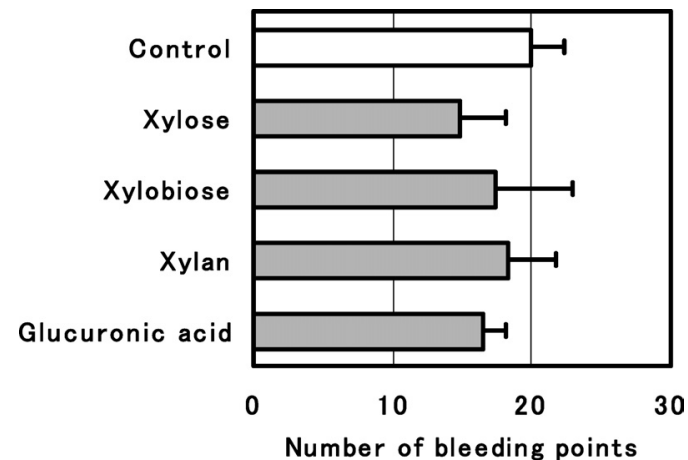

Fig. 4. Inhibitory effects of oral administration of sugars related to acidic xylooligosaccharide on mouse gastritis induced by cold-restraint stress Values are means \pm SEM $(n=4)$. Dose: $100 \mathrm{mg} / \mathrm{kg}$ body weight.

to its suppressive activity on stress-induced mouse gastritis. Acidic xylooligosaccharide may also be expected to show a protective effect against gastric juice simply by coating the surface of the mouse gastric mucosa.

Inhibitory effects of some sugars related to acidic xylooligosaccharide on stress-induced gastric inflammation in mice

The inhibitory effects of some sugars related to acidic xylooligosaccharide on mouse gastric inflammation are shown in Fig. 4. Monomer xylose, dimer xylobiose, and polymer xylan showed no significant suppressive activity on mouse gastric inflammation at the dose of 100 $\mathrm{mg} / \mathrm{kg}$ body weight. Glucuronic acid, the acidic component of acidic xylooligosaccharide, also showed no significant activity at the same dose. Therefore, the active components in acidic xylooligosaccharide are thought to be larger than trimers of xylose. Acidic xylooligosaccharide used in this study included $66.6 \%$ of such oligomers. Glucuronic acid may not be necessary for the anti-inflammatory activity of acidic xylooligosaccharide. We could obtain only crude xylooligosaccharide, and this showed significant suppressive activity on mouse gastric inflammation at the dose of $100 \mathrm{mg} / \mathrm{kg}$ body weight (data not shown). However, its purity was low (43.3\%), and further studies are required using a preparation with higher purity. In addition, the mechanism of the suppressive activity of acidic xylooligosaccharides on mouse stress-induced 
gastritis should be further investigated. Recently, acidic xylooligosaccharide from birchwood xylan was reported to show antimicrobial activity against Helicobacter pylori ${ }^{17}$. The, daily intake of acidic xylooligosaccharide larger than trimers at doses not exceeding $300 \mathrm{mg} / \mathrm{kg}$ body weight per day may inhibit stress-induced gastric inflammation in humans, although excessive intake of digestion-resistant oligosaccharides, such as acidic xylooligosaccharide, can cause diarrhea.

\section{References}

1) Biely, P., Microbial xylanolytic systems. Trends in Biotechnol., 3, 286-290 (1985).

2) Mizuno, T., Wasa, T., Ito, H, Suzuki, C., Ukai, N., Antitumor-active polysaccharides isolated from the fruiting body of Hericium erinaceum, an edible and medicinal mushroom called Yamabushitake or Houtou. Biosci. Biotechnol. Biochem., 56, 347-348 (1992).

3) Hashi, M., Takeshita, T., Studies on antitumor activity of wood hemicelluloses. II. The host-mediated antitumor effect of 4-O-methylglucuronoxylan. Agric. Biol. Chem., 43, 961-967 (1979).

4) Whistler, R. L., Bushway, A., Singh, P. P., Nakahara, W., Tokuzen, R., Noncytotoxic, antitumor polysaccharides. Adv. Carbohydr. Chem. Biochem., 32, 235-275 (1976).

5) Yamada, H., Nagai, T., Cyong, J.-C., Otsuka, Y., Relationship between chemical structure and anti-complementary activity of plant polysaccharides. Carbohydr. Res., 144, 101-111 (1985).

6) Samuelsen, A. B., Paulsen, B. S., Wold, J. K., Otsuka, H., Yamada, H., Espevik, T., Isolation and partial characterization of biologically active polysaccharides from Plantago major L. Phytother. Res., 9, 211-218 (1995).

7) Okazaki, M., Koda, H., Izumi, R., Fujikawa, S., Matsumoto, N., In vitro digestibility and in vivo utilization of xylobiose. Nippon Eiyo Shokuryo Gakkaishi, 44, 41-44 (1991).

8) Fujikawa, S., Okazaki, M., Matsumoto, N., Effect of xyl- ooligosaccharide on growth of intestinal bacteria and putrefaction products. Nippon Eiyo Shokuryo Gakkaishi, 44, 37-40 (1991).

9) Imaizumi, K., Nakatsu, Y., Sato, M., Sedarnawati, Y., Sugano, M., Effects of xylooligosaccharides on blood glucose, serum and liver lipids and cecum short-chain fatty acids in diabetic rats. Agric. Biol. Chem., 55, 199205 (1991)

10) Chen, S. H., Lei, H. L., Huang, L. R., Tsai, L. H., Protective effect of excitatory amino acids on cold-restraint stressinduced gastric ulcers in mice: role of cyclic nucleotides. Dig. Dis. Sci., 46, 2,285-2,291 (2001).

11) Nishikimi, M., Rao, N. A., Yagi, K., The occurrence of superoxide anion in the reaction of reduced phenazine methosulfate and molecular oxygen. Biochem. Biophys. Res. Commun., 46, 849-854 (1972).

12) Oyanagui, Y., Various actions of active oxygens on inflammatory processes. Jpn. J. Inflamm., 3, 377-378 (1983).

13) Shingu, M., Todoroki, T., Oribe, M., Tomooka, K., Nobunaga, M. Nakagami, K., Study on the mechanism of oxygen radical-induced inflammation. Jpn. J. Inflamm., 2, 367-368 (1982).

14) Alptekin, N., Seckin, S., Dogru-Abbasoglu, S., KocakToker, N., Cevikbas, U., Uysal, M., Effect of vitamin C on glutathione and lipid peroxide levels in rats exposed to water-immersion restraint stress. Med. Sci. Res., 26, 595597 (1998)

15) Park, P.-J., Je J.-Y., Kim, S.-K., Free radical scavenging activity of chitooligosaccharides by electron spin resonance spectrometry. J. Agric. Food Chem., 51, 4,6244,627 (2003).

16) Kato, I., Antioxidative and antitumorigenic properties of agarooligosaccharide. Bioindustry, 17, 13-19 (2000).

17) Christakopoulos, P., Katapodis, P., Kalogeris, E., Kekos, D., Macris, B. J., Stamatis, H., Skaltsa, H., Antimicrobial activity of acidic xylo-oligosaccharides produced by family 10 and 11 endoxylanases. Int. J. Biol. Macromol., 31, 171-175 (2003). 